Article

\title{
Effects of Coriandrum sativum L. in Association with Physical Exercise in Alloxan-Induced Type 1 Diabetes Mellitus in Rats
}

André L. B. D. Cardoso ${ }^{1,2}{ }^{\circledR}$, Éric H. F. F. Frederico ${ }^{1,3}$, Carlos A. S. Guimarães ${ }^{1}$, Marcia C. Moura-Fernandes 1,2, Eliane O. Guedes-Aguiar ${ }^{1,4}$, Adriana L P da Silva ${ }^{1}$, Aline Reis-Silva ${ }^{1,5}$, Arlete Francisca-Santos ${ }^{1}$, Luiz F. F. de Souza ${ }^{1}$, Rubens Mendonça-Guimarães ${ }^{1}$, Tiago Eduardo-Santos ${ }^{1}$, Diego Eduardo-Santos ${ }^{1}$, Laisa L. Paineiras-Domingos 1,4 ${ }^{\mathbb{D}}$, Danúbia da C. de Sá-Caputo ${ }^{1}{ }^{\circledR}$, Nasser R. Asad ${ }^{1}$, Redha Taiar ${ }^{1,6, *(1)}$ and Mario Bernardo-Filho ${ }^{1}$ (i)

1 Laboratório de Vibrações Mecânicas e Práticas Integrativas, Departamento de Biofísica e Biometria, Instituto de Biologia Roberto Alcantara Gomes e Policlínica Américo Piquet Carneiro, Universidade do Estado do Rio de Janeiro, Rio de Janeiro, 20950-003 RJ, Brazil; andreluisdionizio@hotmail.com (A.L.B.D.C.); ericfrederico@msn.com (É.H.F.F.F.); carlosalbertolinco@hotmail.com (C.A.S.G.); marciafernandesfisio@hotmail.com (M.C.M.-F.); ellianeguedes@gmail.com (E.O.G.-A.); adrianaliriolavimpi@gmail.com (A.L.P.d.S.); fisio.alinereis@hotmail.com (A.R.-S.); fisioarlete@hotmail.com (A.F.-S.); lumadaragu@gmail.com (L.F.F.d.S.); rubens_fisio@hotmail.com (R.M.-G.); tesantos17@gmail.com (T.E.-S.); eudardosantos17@gmail.com (D.E.-S.); laisanit@gmail.com (L.L.P.-D.); dradanubia@gmail.com (D.d.C.d.S.-C.); nasser.ribeiro@gmail.com (N.R.A.); bernardofilhom@gmail.com (M.B.-F.)

2 Programa de Pós-graduação em Fisiopatologia Clínica e Experimental, Faculdade de Ciências Médicas, Universidade do Estado do Rio de Janeiro, Rio de Janeiro, 20551-030 RJ, Brazil

3 Programa de Pós-graduação em Biociências, Instituto de Biologia Roberto Alcantara Gomes, Universidade do Estado do Rio de Janeiro, Rio de Janeiro, 20551-030 RJ, Brazil

4 Programa de Pós-graduação em Ciências Médicas, Faculdade de Ciências Médicas, Universidade do Estado do Rio de Janeiro, Rio de Janeiro, 20551-030 RJ, Brazil

5 Programa de Pós-graduação em Saúde, Medicina Laboratorial e Tecnologia Forense, Universidade do Estado do Rio de Janeiro, Rio de Janeiro, 20551-030 RJ, Brazil

6 Groupe de Recherche En Sciences Pour I'Ingénieur, Université de Reims, 51100 Reims, France

* Correspondence: redha.taiar@univ-reims.fr

Received: 2 November 2019; Accepted: 2 December 2019; Published: 11 December 2019

check for updates

Featured Application: The concomitant treatment proposed by this study could be an important therapeutic tool used to improve the complications arising from type 1 diabetes mellitus and could provide a clinical alternative for those individuals that currently only have the pharmacological path.

Abstract: The treatment of type 1 diabetes mellitus (T1DM) is a health challenge and new approaches to solve this issue have been proposed. This study evaluated the biological effects of a concomitant treatment with Coriandrum sativum (coriander) and whole-body vibration (WBV) exercise on rats with T1DM. It is hypothesized that this concomitant treatment will improve the metabolic state of rats with T1DM. T1DM was induced with alloxan. Male rats $(n=20)$ were divided into four groups: control (CON), treated with coriander (COR), exposed to $50 \mathrm{~Hz}$ of WBV (WBV), and treated with coriander and exposed to $50 \mathrm{~Hz}$ of WBV (COR + WBV), weekly for 28 days. No alterations were observed in the metabolic outcome variables relating to the organs, specific biomarkers, body mass, food intake, and stool consistency. Alloxan-induced T1DM resisted desirable therapeutic effects of the proposed concomitant treatment as it inhibited antidiabetic activity of the coriander. Putting together all findings, neither coriander nor WBV exercise were capable of improving the metabolic 
state of the Wistar rats with T1DM. This data set and the knowledge in the literature about the effects of the concomitant treatment in healthy animals can provide greater reliability concerning the effects of coriander.

Keywords: Coriandrum sativum; Whole-body vibration; type 1 Diabetes mellitus; biodistribution; body mass; food intake

\section{Introduction}

Diabetes mellitus (DM) is a chronic metabolic disease that occurs when the pancreas loses the capacity to make insulin, or when the body cannot properly use the insulin it produces [1]. According to the International Diabetes Federation (IDF), DM affects about 422 million people globally and is a major cause of complications, such as blindness, kidney failure, heart attacks, stroke and lower limb amputation [2]. Type 1 diabetes mellitus (T1DM) is one of the main subtypes of DM, accounting for approximately $10 \%$ of all cases of DM, and has gradually increased over time [2,3].

Some drugs used for the management of DM may maintain blood glucose homeostasis, although with some unfavorable side-effects [3,4]. In turn, medicinal plants with hypoglycemic activities and low adverse effects are gaining importance. Ethno-medical studies revealed that extracts and isolated molecules derived from medicinal plants can be used to treat T1DM [5].

Coriandrum sativum L. is an example of medicinal plant that have been used in the management of insulin and blood glucose levels [6]. Belonging to the Apiaceae family [7], this plant is an annual herb native to the eastern Mediterranean and popularly known as coriander.

Some investigations have shown that coriander extracts could lower blood sugar level $[6,8]$. In addition, in alloxan-induced diabetic mice, coriander demonstrated antidiabetic activity by improving and regenerating the pancreatic $\beta$ cell and inhibiting the $\alpha$-glucosidase enzyme activity [9]. Alloxan is a diabetogenic agent, used to model T1DM in in vivo studies due to producing severe insulin deficiency, as well as marked hyperglycemia, ketoacidosis and glycosuria in experimental models [10]. Sreelatha and Inbavalli [8] have suggested the presence of higher concentrations from flavonoid and total phenolic contents present on the leaf and stem of coriander extract, consistent with the ability of the plant extract to promote insulin and reduce glucose levels, a desirable effect for the treatment of T1DM.

Over time, individuals with T1DM tend to develop health problems that may preclude physical exercise. For example, individuals with proliferative retinopathy are advised against strenuous physical exercise due to the possibility of a vitreous hemorrhage [11]. Thus, a treatment modality which confers the benefits of exercise without the associated physical constraints is desirable.

On the other hand, physical exercise has been shown to be an important component in the treatment of DM, contributing to improvement of metabolism and energy balance, and increase of lean body mass and bone mass [12]. A passive modality of exercise known as whole-body vibration (WBV) exercises, in which the whole body of an individual on the base of a vibratory platform is exposed to mechanical vibrations, has been proposed as a potential alternative, or adjuvant, to physical exercise for those who cannot participate in active exercise due to physical or mental problems $[13,14]$.

Combining the potential benefits of medicinal plants with those of physical exercise, such as WBV, may represent a promising tool to prevent major health risks and diseases $[15,16]$. Although the positive health effects of physical exercise are widely known, there is only a limited understanding of its influence on the immune system, as well as autoimmune diseases including T1DM [17].

WBV is broadly accessible to large populations due to its noninvasive nature, few side effects, relatively low cost, simplicity of application, and short durations required to be effective $[18,19]$. These considerations indicate that WBV exercise may have clinical potential in the management of 
T1DM [18]. This potential has stimulated investigations into WBV exercise using pre-clinical models including rodents [20-22].

In experimental investigations, the course of a plant extract therapy or even WBV intervention can be guided through the altered distribution of a radiopharmaceutical [22,23]. The radiopharmaceutical sodium pertechnetate ( $\mathrm{Na} 99 \mathrm{mTcO} 4)$ is widely used in experimental investigations [24]. In addition, physiological parameters as body mass, food intake and stool consistency help to understand which changes the concomitant intervention can provide in the long term [25]. The current study aimed to evaluate the effect of concomitant treatment of an aqueous extract of coriander and WBV exercise on physiological parameters, such as biodistribution of the radiopharmaceutical sodium pertechnetate $\left(\mathrm{Na}^{99 \mathrm{~m}} \mathrm{TcO}^{4}\right)$, concentration of specific plasma biomarkers, body mass, food intake, and stool consistency in Wistar rats with T1DM. Considering this type of approach as a promising tool for future clinical studies with DM, we hypothesized that treatment with coriander accompanied with WBV exercise will improve the metabolic state of rats with T1DM.

\section{Material and Methods}

\subsection{Animals and Ethical Approach}

Wistar rats ( $\mathrm{n}=20,243.1 \pm 34.0 \mathrm{~g}), 3-4$ months old, were maintained at an average temperature of $25 \pm 2{ }^{\circ} \mathrm{C}$, a relative humidity of $55 \%$, and a light/dark cycle of $12 \mathrm{~h}$. All rates were provided with a standard diet and water ad libitum. Experiments were performed following the guidelines of the Comitê de Ética Para o Uso de Animais Exprimentais (CEUA), Instituto de Biologia Roberto Alcantara Gomes (IBRAG), which approved the investigation (CEUA/041/2013).

\subsection{Induction of Diabetes}

Diabetes was induced by intraperitoneal injection with $150 \mathrm{mg} / \mathrm{kg}$ alloxan monohydrate (Sigma-Aldrich, St Louis, MO, USA) freshly prepared in $0.9 \% \mathrm{NaCl}$ [19]. A single dose was administered to rats via a $0.5 \mathrm{~mL}$ syringe/needle. The diabetes status of rats was confirmed after 1 week. Rats with fasting glucose levels of $\geq 11.1 \mathrm{mmol} / \mathrm{L}(200 \mathrm{mg} / \mathrm{dL}$ ) were considered with diabetes [26].

\subsection{Preparation of the Aqueous Extract of Coriander}

A commercial dry seed of coriander (Coriandrum sativum L.) was used (lot 015, expiration date on July 2019, Distribuidora de Cereais Crowne Ltda, Rio de Janeiro, Brazil). To prepare the extract, $80 \mathrm{mg}$ of coriander were added to $10 \mathrm{~mL}$ of deionized water. Then, the preparation was vortexed for $1 \mathrm{~min}$, centrifuged (clinical centrifuge, $1500 \mathrm{rpm}, 15 \mathrm{~min}$ ) and the supernatant was considered to be $8 \mathrm{mg} / \mathrm{mL}$ of coriander. The preparation of the extract was controlled by spectrophotometric analysis (extract with optical density at $480 \mathrm{~nm}$ ) [27].

\subsection{Experimental Procedures}

Wistar rats with T1DM $(n=20)$ were randomly divided into four groups: control group $(C O N)$, group treated with Coriander (COR), group exposed to $50 \mathrm{~Hz}$ of WBV (WBV), and treated with coriander and exposed to $50 \mathrm{~Hz}$ of WBV (COR + WBV). Along 28 days the CON group received by gavage [28] $1.0 \mathrm{~mL}$ of deionized water, while the group COR received by gavage $1.0 \mathrm{~mL}$ of aqueous extract at $8 \mathrm{mg} / \mathrm{mL}$. In addition, the group WBV received $1.0 \mathrm{~mL}$ of deionized water and group COR $+\mathrm{WBV}$ received $1.0 \mathrm{~mL}$ of aqueous extract at $8 \mathrm{mg} / \mathrm{mL}$, and then were submitted daily to vibration. Experimental procedures were applied for 5 days/week for 4 weeks. The experimental variables used in this current study were similar to our previous study [25].

WBV exercise was applied every day between 11:00 and 12:00 through a vertically oscillating vibratory plate with the base oscillating up and down at the same time in a synchronous way (synchronous platform) (Globus G-Vibe 800, Italy). Sinusoidal vertical vibrations were generated with 
the following biomechanical variables: $50 \mathrm{~Hz}$ frequency, $0.78 \mathrm{~mm}$ amplitude, and peak acceleration of $7.85 \mathrm{~g}$.

\subsection{Biodistribution of Radiopharmaceutical $\mathrm{Na}^{99 m} \mathrm{TcO}_{4}$}

One day after the treatments (29th day), the rats were anesthetized with ketamine $(75 \mathrm{mg} / \mathrm{kg}$ ) and xylazine $\left(10 \mathrm{mg} / \mathrm{kg}\right.$ ) [29], and then given $0.3 \mathrm{~mL}(550 \mathrm{kBq})$ of the radiopharmaceutical $\mathrm{Na}^{99 \mathrm{~m}_{\mathrm{TcO}}}$ $\left(1.85 \mathrm{MBq} / \mathrm{mL}\right.$ ) via ocular plexus. The $\mathrm{Na}^{99 \mathrm{~m}} \mathrm{TcO}_{4}$ was eluted (60 min prior) from a ${ }^{99} \mathrm{Mo} /{ }^{99 \mathrm{~m}} \mathrm{Tc}$ generator (Frederico et al., 2017a). The assays were performed in the clinical laboratory of the Universidade do Estado do Rio de Janeiro in an automated manner (COBAS INTEGRA 400 plus, Roche, Basel, Switzerland). Rats were killed by $\mathrm{CO}_{2}$ asphyxiation following the Conselho Nacional de Controle de Experimentação Animal (CONCEA) guideline and the organs (thyroid, stomach, bowel, kidney, liver, pancreas, bone, lung, heart, spleen, muscle and bladder) were harvested and radioactivity was determined in a well counter. Percentages of the injected radioactivity per gram (\%ATI/g) in the organs were calculated as reported elsewhere [25].

\subsection{Blood Biochemical Analysis}

After 28 days of treatment, during the biodistribution procedure blood samples were collected by cardiac puncture to analyze the effect on organs. The concentrations of selected biomarkers (glucose, urea, creatinine, cholesterol, triglyceride, high density lipoprotein (HDL), total bilirubin, direct bilirubin, calcium, magnesium, total protein and albumin) were measured. Furthermore, the concentration of some enzymes (amylase, lipase, creatine kinase (CK), aspartate aminotransferase (AST), alanine aminotransferase (ALT), alkaline phosphatase (ALP) was also measured. The assays were performed in the clinical laboratory of the Universidade do Estado do Rio de Janeiro in an automated manner (COBAS INTEGRA 400 plus, Roche, Basel, Switzerland).

\subsection{Body Mass Analysis}

Body mass of each animal was determined weekly with a digital balance (FILIZOLA BP6, São Paulo, Brazil). The relative (percent) change in body mass was calculated as the body mass ratio between each week and the first day (and multiplied by 100).

\subsection{Food Intake Analysis}

A quantity of $500 \mathrm{~g}$ of feed was supplied daily to each group. The following day, leftover food was counted on a digital balance (FILIZOLA BP6, São Paulo, Brazil). The feed intake was calculated as the difference between the supplied $500 \mathrm{~g}$ and the leftover food on each day. This number was divided by 5 (number of rats per group).

\subsection{Stool Consistency Analysis}

Stool consistency was analyzed using a form scale. Three different and independent evaluators daily analyzed the consistency of the stool and chose a value according to the scale. Values ranged from 1 to 4 as described [25] with Type 1 being hard, dry, and dark stool, Type 2 being normal with cracks in the surface, Type 3 being smooth and soft, and Type 4 being fluffy pieces with ragged edges (mushy stool). The median of these three analyses was considered. The stool sample was collected before the animals' gavage.

\subsection{Statistical Analysis}

The statistical analysis of the data was performed with the aid of BioEstat 5.3 software (Instituto Mamiraua, Pará, Brazil). A normality test was done to determine if the data set was well-modeled by a normal distribution. As all data did not follow a normal distribution, a Kruskal-Wallis test was performed. Data were presented as mean \pm standard deviation $( \pm \mathrm{SD})$, median \pm interquartile 
range (IQR) or as percentage (\%). Statistical significance was accepted at $p<0.05$. Epsilon-squared $\left(\varepsilon^{2}\right)$ was used to estimate the effect size. The $\varepsilon^{2}$ assumes a value from 0 (indicating no relationship) to 1 (indicating a perfect relationship). Effect sizes were analyzed to determine the magnitude of an effect independent of sample size, as reported elsewhere [30]. The $\varepsilon^{2}$ effect sizes were measured by the formula: $\varepsilon^{2}=\frac{H}{n^{2}+1 / n+1}$, where $H$ is the value obtained from the Kruskal-Wallis test (the Kruskal-Wallis H-test statistic) and $n$ is the total number of observations.

\section{Results}

\subsection{Effect of Coriander and/or WBV on Biodistribution of Sodium Pertechnetate $\left(\mathrm{Na}^{99 m} \mathrm{TcO}_{4}\right)$}

Table 1 shows the percentage of the injected dose (\%ATI/g) of the $\mathrm{Na}^{99 \mathrm{~m}} \mathrm{TcO}_{4}$ in the various organs isolated from the animals submitted to the different treatments. No differences were found on uptake of $\mathrm{Na}^{99 \mathrm{~m}} \mathrm{TcO}_{4}$ in the organs isolated from the rats with T1DM. The values of $\varepsilon^{2}$ ranged from 0.05 to 0.36 , indicating no effect size.

Table 1. \%ATI/g of the $\mathrm{Na}^{99} \mathrm{TcO}_{4}$ in the various organs isolated from rats with type 1 diabetes mellitus (T1DM) and exposed to the different treatments.

\begin{tabular}{ccccccc}
\hline ORGANS & CON & COR & WBV & COR + WBV & $p$ & $\varepsilon^{2}$ \\
\hline Thyroid & $5.17 \pm 2.19$ & $5.13 \pm 3.35$ & $6.97 \pm 0.95$ & $6.85 \pm 1.70$ & 0.26 & 0.26 \\
Stomach & $5.05 \pm 1.35$ & $6.86 \pm 1.28$ & $5.95 \pm 1.26$ & $5.29 \pm 2.71$ & 0.23 & 0.29 \\
Bowel & $1.24 \pm 0.32$ & $3.06 \pm 1.75$ & $1.40 \pm 0.00$ & $1.42 \pm 0.68$ & 0.24 & 0.28 \\
Kidney & $1.22 \pm 0.41$ & $1.13 \pm 0.57$ & $1.47 \pm 0.15$ & $1.17 \pm 0.22$ & 0.75 & 0.08 \\
Liver & $1.40 \pm 0.24$ & $1.32 \pm 0.41$ & $1.38 \pm 0.02$ & $1.26 \pm 0.16$ & 0.55 & 0.14 \\
Pancreas & $1.09 \pm 0.32$ & $0.90 \pm 0.50$ & $1.02 \pm 0.04$ & $0.87 \pm 0.49$ & 0.85 & 0.05 \\
Bone & $0.30 \pm 0.12$ & $0.34 \pm 0.15$ & $0.54 \pm 0.14$ & $0.36 \pm 0.12$ & 0.14 & 0.36 \\
Lung & $1.60 \pm 0.78$ & $1.25 \pm 0.66$ & $2.08 \pm 0.01$ & $1.29 \pm 0.34$ & 0.37 & 0.21 \\
Heart & $0.67 \pm 0.26$ & $0.60 \pm 0.47$ & $0.91 \pm 0.26$ & $0.55 \pm 0.14$ & 0.38 & 0.21 \\
Spleen & $0.72 \pm 0.24$ & $0.58 \pm 0.30$ & $0.85 \pm 0.16$ & $0.59 \pm 0.16$ & 0.33 & 0.23 \\
Muscle & $0.17 \pm 0.06$ & $0.22 \pm 0.12$ & $0.30 \pm 0.04$ & $0.21 \pm 0.05$ & 0.28 & 0.25 \\
Bladder & $0.65 \pm 0.17$ & $0.78 \pm 0.25$ & $1.00 \pm 0.37$ & $1.15 \pm 0.71$ & 0.44 & 0.18
\end{tabular}

$\mathrm{CON}$, control group; $\mathrm{COR}$, group treated with coriander, $\mathrm{WBV}$, group submitted to mechanical vibration generated in platform; COR + WBV, group treated with coriander and submitted to vibration. Values are shown as the means $\pm \mathrm{SD}, p, \varepsilon^{2}$.

\subsection{Effect of Coriander and/or WBV on a General Biochemical Analysis}

After 28 days of treatment, no differences were found in the plasma concentration of the evaluated biomarkers of rats with T1DM submitted to the various treatments (Table 2). The values of $\varepsilon^{2}$ ranged from 0.01 to 0.38 .

Table 2. Concentration of selected plasma biomarkers determined in rats with.

\begin{tabular}{ccccccc}
\hline Biomarkers & CON & COR & WBV & COR + WBV & $p$ & $\varepsilon^{2}$ \\
\hline Glucose $(\mathrm{mmol} / \mathrm{L})$ & $36.1 \pm 2.32$ & $37.30 \pm 3.88$ & $39.69 \pm 0.19$ & $38.40 \pm 2.29$ & 0.32 & 0.24 \\
Urea $(\mathrm{mmol} / \mathrm{L})$ & $14.71 \pm 3.82$ & $15.40 \pm 3.57$ & $20.81 \pm 7.05$ & $16.45 \pm 5.39$ & 0.56 & 0.14 \\
Creatinine $(\mu \mathrm{mol} / \mathrm{L})$ & $31.82 \pm 7.96$ & $38.01 \pm 8.84$ & $35.36 \pm 12.38$ & $33.59 \pm 7.07$ & 0.74 & 0.08 \\
Cholesterol $(\mathrm{mmol} / \mathrm{L})$ & $1.66 \pm 0.39$ & $1.88 \pm 0.88$ & $1.98 \pm 0.53$ & $1.60 \pm 0.32$ & 0.70 & 0.10 \\
Triglycerides $(\mathrm{mmol} / \mathrm{L})$ & $1.74 \pm 0.75$ & $1.75 \pm 0.85$ & $1.75 \pm 0.60$ & $1.83 \pm 1.03$ & 0.99 & 0.01 \\
HDL $(\mathrm{mmol} / \mathrm{L})$ & $1.49 \pm 0.23$ & $1.39 \pm 0.18$ & $1.53 \pm 0.02$ & $1.35 \pm 0.21$ & 0.52 & 0.15 \\
Total Bilirubin $(\mu \mathrm{mol} / \mathrm{L})$ & $2.05 \pm 0.51$ & $1.71 \pm 0.34$ & $2.22 \pm 0.17$ & $2.05 \pm 0.34$ & 0.40 & 0.20 \\
Direct Bilirubin $(\mu \mathrm{mol} / \mathrm{L})$ & $0.86 \pm 0.17$ & $0.86 \pm 0.31$ & $1.20 \pm 0.51$ & $0.68 \pm 0.34$ & 0.70 & 0.09 \\
Calcium $(\mathrm{mmol} / \mathrm{L})$ & $2.50 \pm 0.07$ & $2.65 \pm 0.23$ & $2.52 \pm 0.15$ & $2.60 \pm 0.13$ & 0.50 & 0.16 \\
Magnesium $(\mathrm{mmol} / \mathrm{L})$ & $1.03 \pm 0.04$ & $1.11 \pm 0.12$ & $1.07 \pm 0.12$ & $1.11 \pm 0.08$ & 0.42 & 0.19 \\
Total Protein $(\mathrm{g} / \mathrm{L})$ & $0.57 \pm 0.03$ & $0.53 \pm 0.07$ & $0.57 \pm 0.03$ & $0.56 \pm 0.05$ & 0.68 & 0.10 \\
Albumin $(\mathrm{g} / \mathrm{L})$ & $0.32 \pm 0.02$ & $0.31 \pm 0.01$ & $0.30 \pm 0.07$ & $0.32 \pm 0.01$ & 0.35 & 0.22 \\
\hline
\end{tabular}

$\mathrm{CON}$, control group; $\mathrm{COR}$, group treated with coriander; $\mathrm{WBV}$, group submitted to mechanical vibration generated in platform; COR + WBV, group treated with coriander and submitted to vibration. HDL, high-density lipoprotein; AST, aspartate aminotransferase; ALT, alanine aminotransferase; CK, creatine kinase. Values are shown as the means \pm SD. $\varepsilon^{2}$ - epsilon squared. 


\subsection{Effect of Coriander and/or WBV on the Enzymatic Activities}

As shown in Figure 1, after four weeks of treatment, no differences were found. The $\varepsilon^{2}$ indicated no relationship.
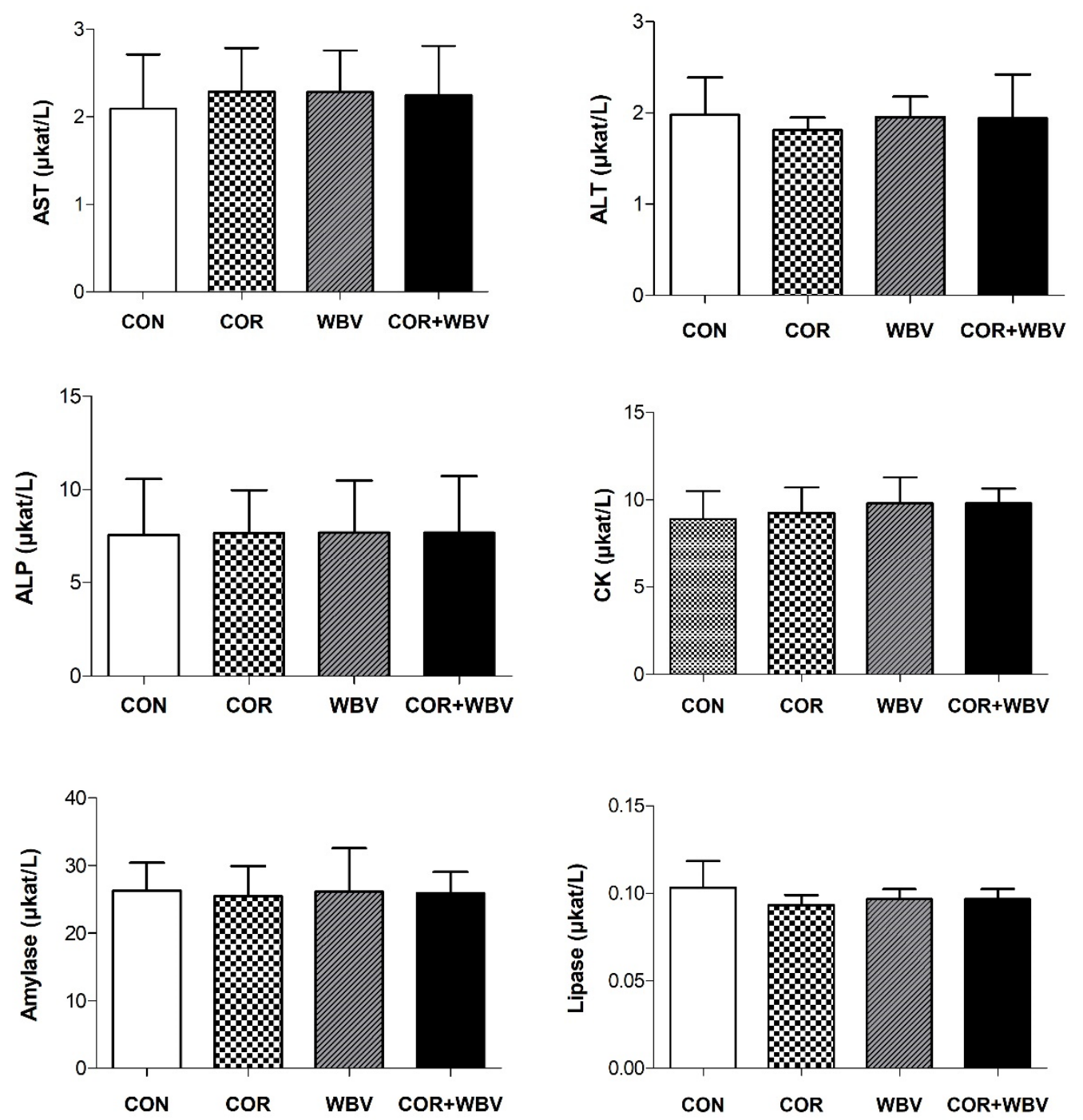

Figure 1. Enzymes determined in animals submitted to different treatments. CON, control group; COR, group treated with coriander; WBV, group submitted to mechanical vibration generated in platform; COR + WBV, group treated with coriander and submitted to vibration; $\mu \mathrm{Kat} / \mathrm{L}$, microkatal; ALP, alkaline phosphatase; ALT, alanine aminotransferase. Values are mean $\pm \mathrm{SD}$.

\subsection{Effect of Coriander and/or WBV on Body Mass}

After 28 days, no differences were observed in percentage body mass of rats with T1DM (Table 3). The values of $\varepsilon^{2}$ ranged from 0.01 to 0.05 . During the first week, an increase of approximately $16 \%$ (non-significant) in percentage body mass was observed in rats of all groups. Further, the percentage body mass of rats exposed to WBV exercise showed a reduction (non-significant) at the end of the experimental study, a difference that was not observed in the other groups. 
Table 3. The body mass (\%) of rats with T1DM exposed to different treatments.

\begin{tabular}{ccccccc}
\hline Week & CON & COR & WBV & COR + WBV & $p$ & $\varepsilon^{2}$ \\
\hline 0 & $100.0 \pm 0.0$ & $100.0 \pm 0.0$ & $100.0 \pm 0.0$ & $100.0 \pm 0.0$ & 0.98 & 0.01 \\
1 & $116.1 \pm 17.4$ & $112.0 \pm 13.0$ & $117.6 \pm 12.7$ & $116.4 \pm 12.6$ & 0.85 & 0.05 \\
2 & $116.4 \pm 14.4$ & $105.9 \pm 16.8$ & $102.0 \pm 16.2$ & $116.6 \pm 9.9$ & 0.37 & 0.02 \\
3 & $117.2 \pm 16.4$ & $110.5 \pm 17.8$ & $108.9 \pm 11.0$ & $116.6 \pm 11.2$ & 0.72 & 0.04 \\
4 & $116.7 \pm 16.1$ & $109.0 \pm 19.6$ & $103.9 \pm 18.9$ & $115.1 \pm 07.4$ & 0.74 & 0.05 \\
\hline
\end{tabular}

$\mathrm{CON}$, control group; $\mathrm{COR}$, group treated with coriander; $\mathrm{WBV}$, group submitted to mechanical vibration generated in platform; COR + WBV, group treated with coriander and submitted to vibration. "0" was the first measurement of the mass of the animals. Values are shown as the median $\pm \mathrm{SD}, p, \varepsilon^{2}$.

\subsection{Effect of Coriander and/or WBV on Food Intake}

The food intake of rats with diabetes subjected to the different interventions indicated no significant difference amongst the groups (Figure 2). The $\varepsilon^{2}$ (not shown in the figure) was 0.07 , indicating no effect size.

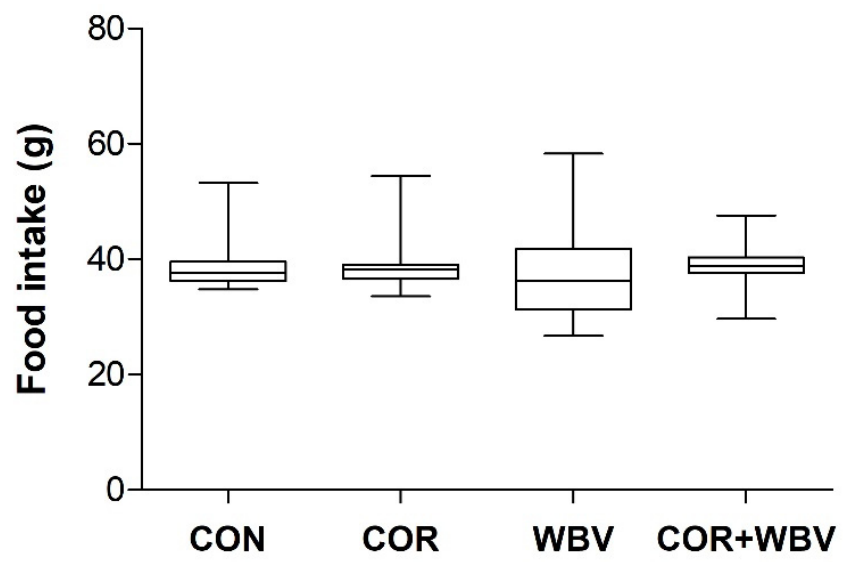

Figure 2. Food intake of rats with T1DM exposed to different treatments.

\subsection{Effect of Coriander and/or WBV on Stool Consistency}

This study used a stool scale adapted for Wistar rats by Frederico et al. (2017) that defined four types of stools (hard, 1; normal, 2; soft middle, 3; and fluffy, 4). The type of feces most identified was type 2. No differences were found in stool consistency (Table 4). The $\varepsilon^{2}$ ranged between 0.11 and 0.33 , indicating a small relationship.

Table 4. Stool consistency of rats with T1DM subjected to different treatments.

\begin{tabular}{ccccccc}
\hline Day & CON & COR & WBV & COR + WBV & $p$ & $\varepsilon^{2}$ \\
\hline $01-07$ & $2.00 \pm 0.00$ & $2.00 \pm 0.00$ & $2.00 \pm 0.00$ & $2.00 \pm 0.00$ & 0.55 & 0.11 \\
$08-14$ & $2.00 \pm 0.00$ & $2.00 \pm 0.00$ & $2.00 \pm 1.00$ & $2.00 \pm 0.00$ & 0.13 & 0.30 \\
$15-21$ & $2.00 \pm 0.00$ & $2.00 \pm 1.00$ & $2.00 \pm 0.00$ & $2.00 \pm 0.00$ & 0.25 & 0.22 \\
$22-28$ & $2.00 \pm 0.00$ & $2.00 \pm 1.00$ & $2.00 \pm 0.00$ & $2.00 \pm 0.00$ & 0.10 & 0.33 \\
\hline
\end{tabular}

$\mathrm{CON}$, control group; $\mathrm{COR}$, group treated with coriander; $\mathrm{WBV}$, group submitted to mechanical vibration generated in platform; COR $+\mathrm{WBV}$, group treated with coriander and submitted to vibration. Values are mean $\pm \mathrm{SD}, p, \varepsilon^{2}$.

\section{Discussion}

The lack of information on the effects of a hypoglycemic medicinal plant and low-intensity physical exercise on the management of T1DM $[15,16]$ stimulated the current study. It was hypothesized that the combination of coriander and WBV exercise may improve some metabolic conditions associated with T1DM. WBV exercise was selected because it is easily accessible to large populations, is non-invasive, has few side effects, is low cost and simple, and doesn't need to be applied for long durations to become 
effective $[18,19]$. Likewise, coriander is one of the most common herbs claimed to lower blood glucose levels, making it potentially useful for the treatment of DM. In this study, the effect of the combination of coriander and WBV exercise on Wistar rats with T1DM was tested via analysis of organs (through biodistribution of $\mathrm{Na}^{99 \mathrm{~m}} \mathrm{TcO}_{4}$ ), plasma biomarkers, body mass, feed intake and stool consistency.

We did not find altered uptake (\%ATI/g) of $\mathrm{Na}^{99} \mathrm{~m}_{\mathrm{TCO}}$ in the studied organs, indicating that WBV and/or coriander were not capable of promoting changes in biochemical/physiological variables in organs of rats with T1DM. In a previous study using healthy rats [25], the results were similar to those observed here. Our data are also similar to those of Ogawa et al. [31], who did not observe significant differences in the radiopharmaceutical ${ }^{18} \mathrm{~F}$-sodium fluoride uptake ratio in bone surrounding implants between rats subjected to WBV exercise and controls. On the other hand, Amin et al. [32] reported a physiological influence of WBV exercise on the image quality related to skeletal scintigraphy with the radiopharmaceutical ${ }^{99 \mathrm{~m}} \mathrm{Tc}-$ methylene diphosphonate $\left({ }^{99 \mathrm{~m}} \mathrm{Tc}-\mathrm{MDP}\right)$ by increasing the ${ }^{99 \mathrm{~m}} \mathrm{Tc}-\mathrm{MDP}$ osseous uptake. However, they neither reported the vibration device used nor the specific vibration variables.

The 28 days of interventions with coriander and/or WBV exercise showed no differences in the plasma biomarker concentrations. This finding agrees with our previous work, done in healthy rats [25] using the same vibration variables. In another study [33], a decrease in amylase was found with WBV exercise. [34] Monteiro et al. 2017 also found a decrease in LDL (low-density lipoprotein) levels after exposure to $10 \mathrm{~Hz}$ whole body vibration. It is likely that differences in results can be attributed to different vibration devices (side-alternating system versus linear motions) and specific vibration variables used (e.g., frequency and acceleration). Erceg et al. [35] also demonstrated no significant differences for bone biomarkers in a 10-week WBV exercise $(30-40 \mathrm{~Hz})$ program in overweight Latino boys.

Coriander and/or WBV exercise had no effect on body mass, consistent with [25], who used an identical experimental design but in healthy young adult male rats. Chen et al. [36] reported that body mass in WBV exercise mice did not change significantly during a six-week experiment period compared to sedentary controls and WBV + dehydroepiandrosterone (DHEA) treated mice. In addition, Sun et al. [37] reported no significant differences in body mass between controls and WBV rats subjected to either a high-fat diet or normal diet. Lin et al. [38] also showed no differences in body mass of middle-aged mice with or without a four-week WBV exercise regimen. On the other hand, de Vries et al. (2014) reported that after diabetes mellitus diagnosis, mass and body mass index increased rapidly, with the most rapid weight gain during the first two weeks in children and adolescents with T1DM. In relation to coriander, Aissaoui et al. [6] found that daily oral administration for 30 days to obese-hyperglycemic-hyperlipidemic Meriones shawi rats did not have any significant effect on body mass.

Considering the food intake after four weeks in T1DM rats subjected to the concomitant treatment, no differences were observed amongst the groups. This finding shows that DM influences the intake of these animals even in those submitted to WBV exercise. In our previous studies $[25,39]$ using the same concomitant protocol, although performed in healthy animals, we observed an increase in feed intake in the animals exposed to WBV exercise. Our present finding corroborates with Chen et al. [36], which demonstrated that WBV exercise and/or DHEA supplementation did not alter food intake in mice.

Despite coriander being used for the treatment of some gastrointestinal disorders, including diarrhea [40], we did not observe altered stool consistency. This could be due to malabsorption or pelvic nerve damage caused by diabetes peripheral neuropathy, which may increase bowel movement frequency [41], therefore minimizing the effect of coriander. Frederico et al. [25] demonstrated an alteration in stool consistency in healthy rats that consumed only coriander (and compared to other groups). The different health conditions of the animals reported ([40] and [25]) may explain the differential findings regarding stool consistency. Moreover, the findings in the current study corroborate those of Cardoso et al. [39], who investigated the effect of WBV exercise and an aqueous extract of Chenopodium ambrosioides in male Wistar rats. They also showed no alteration in stool consistency. 
The concomitant treatment proposed in the present study was not able to alter the metabolic outcome variables in animals with T1DM as we expected. Factors such as the alloxan drug, as the model of DM chosen for this study, could be relevant to the differential results found, although our hypothesis was based on existing results in the literature about the effects of coriander on diabetes (both induced by streptozotocin and alloxan) and of WBV on the selected metabolic variables.

Some limitations of the current study should be considered. For instance, only a limited number of hormones were measured, while others such as insulin were not investigated. An analysis of glycated hemoglobin (HbA1) would be interesting for the diagnosis of DM. Further, we only studied one specific vibration regime and it is possible that an intervention with a different vibration frequency, vibration magnitude, or vibration duration would have produced significant effects.

\section{Conclusions}

Putting together all the findings, we conclude that neither coriander nor WBV exercise were capable of improving the metabolic state of Wistar rats with T1DM. If results from this present study with rodents could be directly translated to humans, they would indicate that the administration of insulin will continue to be necessary for individuals with T1DM. However, further studies involving the use of medicinal plants and WBV exercises on animals with diabetes are needed.

It is possible that, for these conditions, concomitant treatment involving physical exercise and the use of medicinal plants could be a promising tool. In a therapeutic approach, such treatment could provide an alternative for those individuals that currently only have the option to take insulin (which is expensive and has side effects) to treat diabetes.

This data set and knowledge of the joint treatment of coriander with WBV can provide greater reliability concerning the effects of coriander and a reference for new scientific studies.

Author Contributions: A.L.B.D.C. submitted the animals to the mechanical vibration, did the animals' gavage, the stool consistency analyses, the feed intake and the body mass mensuration, and he drafts the manuscript. E.H.F.F.F., C.A.S.G., M.C.M.-F., E.O.G.-A., A.L.P.d.S., A.R.-S., A.F.-S., L.F.F.d.S., R.M.-G., T.E.-S., D.E.-S. and L.L.P.-D., helped on the animals' gavage, the feed intake and the body mass mensuration and blood collection. D.d.C.d.S.-C. and N.R.A. also did the statistical analysis. R.T. helped on the draft of manuscript. M.B.-F. coordinated the study and helped on the draft of the manuscript.

Funding: This research was funded by Coordenação de Aperfeiçoamento de Pessoal de Nível Superior-Brazil (CAPES)-Finance Code 001, Conselho Nacional de Pesquisa e Desenvolvimento Científico e Tecnológico (CNPq) and Fundação de Amparo à pesquisa do Estado do Rio de Janeiro (FAPERJ).

Conflicts of Interest: The authors declare that they have no conflicts of interest associated with this publication and there has been no significant financial support for this work that could have influenced its outcome.

\section{References}

1. Zimmet, P.Z.; Magliano, D.J.; Herman, W.H.; Shaw, J.E. Diabetes: A 21st century challenge. Lancet Diabetes Endocrinol. 2014, 2, 56-64. [CrossRef]

2. Ogurtsova, K.; da Rocha Fernandes, J.D.; Huang, Y.; Linnenkamp, U.; Guariguata, L.; Cho, N.H.; Makaroff, L.E. IDF Diabetes Atlas: Global estimates for the prevalence of diabetes for 2015 and 2040. Diabetes Res. Clin. Pract. 2017, 128, 40-50. [CrossRef] [PubMed]

3. Tuomi, T.; Santoro, N.; Caprio, S.; Cai, M.; Weng, J.; Groop, L. The many faces of diabetes: A disease with increasing heterogeneity. Lancet 2014, 383, 1084-1094. [CrossRef]

4. Meier, C.; Schwartz, A.V.; Egger, A.; Lecka-Czernik, B. Effect of diabetes drugs on the skeleton. Bone 2015, 82, 93-100. [CrossRef] [PubMed]

5. Kumar, S.; Patial, V.; Soni, S.; Sharma, S.; Pratap, K.; Kumar, D.; Padwad, Y. Picrorhiza kurroa enhances $\beta$-cell mass proliferation and insulin secretion in streptozotocin evoked $\beta$-cell damage in rats. Front. Pharmacol. 2017, 8, 537. [CrossRef] [PubMed]

6. Aissaoui, A.; Zizi, S.; Israili, Z.H.; Lyoussi, B. Hypoglycemic and hypolipidemic 441 effects of Coriandrum sativum L. in Meriones shawi rats. J. Ethnopharmacol. 2011, 442, 652-661. [CrossRef] [PubMed] 
7. Laribi, B.; Koukz, K.; M'Hamdi, M.; Bettaieb, T. Coriander (Coriandrum sativum L.) and its bioactive constituents. Fitoterapia 2015, 103, 9-26. [CrossRef]

8. Sreelatha, S.; Inbavalli, R. Antioxidant, Antihyperglycemic, and Antihyperlipidemic Effects of Coriandrum sativum Leaf and Stem in Alloxan-Induced Diabetic Rats. J. Food Sci. 2012, 77, 119-123. [CrossRef]

9. Aligita, W.; Susilawati, E.; Septiani, H.; Atsil, R. Antidiabetic Activity of Coriander (Coriandrum Sativum L.) Leaves' Ethanolic Extract. Int. J. Pharm. Phytopharmacol. Res. 2018, 8, 59-63.

10. Lenzen, S. The mechanisms of alloxan-and streptozotocin-induced diabetes. Diabetologia 2008, 51, $216-226$. [CrossRef]

11. Colberg, S.R.; Sigal, R.J.; Yardley, J.E.; Riddell, M.C.; Dunstan, D.W.; Dempsey, P.C.; Horton, E.S.; Castorino, K.; Tate, D.F. Physical activity/exercise and diabetes: A position statement of the American Diabetes Association. Diabetes Care 2016, 39, 2065-2079. [CrossRef] [PubMed]

12. Francesconi, C.; Lackinger, C.; Weitgasser, R.; Haber, P.; Niebauer, J. Physical activity and exercise training in the prevention and therapy of type 2 diabetes mellitus. Wien. Klin. Wochenschr. 2016, 128, 141-145. [CrossRef] [PubMed]

13. Cochrane, D.J. Vibration exercise: The potential benefits. Int. J. Sports Med. 2010, 32, 75-99. [CrossRef] [PubMed]

14. Giombini, A.; Menotti, F.; Laudani, L.; Piccinini, A.; Fagnani, F.; Di Cagno, A.; Pigozzi, F. Effect of whole body vibration frequency on neuromuscular activity in ACL-deficient and healthy males. Biol. Sport 2015, 32, 243. [CrossRef] [PubMed]

15. Ali, B.H.; Karaca, T.; Al Suleimani, Y.; Al Za'abi, M.; Al Kalbani, J.; Ashique, M.; Nemmar, A. The effect of swimming exercise on adenine-induced kidney disease in rats, and the influence of curcumin or lisinopril thereon. PLoS ONE 2017, 12, e0176316. [CrossRef]

16. Alkhatib, A.; Atcheson, R. Yerba Maté (Ilex paraguariensis) Metabolic, Satiety, and Mood State Effects at Rest and during Prolonged Exercise. Nutrients 2017, 9, 882. [CrossRef]

17. Sharif, K.; Watad, A.; Bragazzi, N.L.; Lichtbroun, M.; Amital, H.; Shoenfeld, Y. Physical activity and autoimmune diseases: Get moving and manage the disease. Autoimmun. Rev. 2018, 17, 53-72. [CrossRef]

18. Kessler, N.J.; Hong, J. Whole body vibration therapy for painful diabetic peripheral neuropathy: A pilot study. J. Bodyw. Mov. Ther. 2013, 17, 518-522. [CrossRef]

19. Jing, D.; Yan, Z.; Cai, J.; Tong, S.; Li, X.; Guo, Z.; Luo, E. Low-1 level mechanical vibration improves bone microstructure, tissue mechanical properties and porous titanium implant osseointegration by promoting anabolic response in type 1 diabetic rabbits. Bone 2017, 106, 11-21. [CrossRef]

20. Weinheimer-Haus, E.M.; Judex, S.; Ennis, W.J.; Koh, T.J. Low-intensity vibration improves angiogenesis and wound healing in diabetic mice. PLoS ONE 2014, 9, e91355. [CrossRef]

21. Pawlak, M.; Kaczmarek, D.; Nowak, A.; Krutki, P. Low-volume whole-body vibration lasting 3 or 6 months does not affect biomarkers in blood serum of rats. Acta Physiol. Hung. 2013, 100, 48-53. [CrossRef] [PubMed]

22. Keijser, J.N.; van Heuvelen, M.J.G.; Nyakas, C.; Tóth, K.; Schoemaker, R.G.; Zeinstra, E.; van der Zee, E.A. Whole body vibration improves attention and motor performance in mice depending on the duration of the whole-body vibration session. Afr. J. Tradit. Complement. Altern. Med. 2017, 14, 128-134. [CrossRef] [PubMed]

23. Vaisberg, M.; Pereira, M.O.; Souza, D.E.; Bernardo-Filho, M.; Santos-Filho, S.D.; Fonseca, A.S.; Brito, L.C. Does acute swimming exercise alter the bioavailability of the radiopharmaceutical technetium-99m methylenediphosphonate (99mTc-MDP) in Wistar rats? Anim. Biol. 2011, 61, 403-412. [CrossRef]

24. Góes, V.C.; Neves, R.H.; Arnóbio, A.; Bernardo-Filho, M.; Machado-Silva, J.R. Streptozotocin (STZ) and schistosomiasis mansoni change the biodistribution of radiopharmaceutical sodium $99 \mathrm{mTc}$-pertechnetate in mice. Nucl. Med. Biol. 2016, 43, 581-586. [CrossRef]

25. Frederico, E.H.F.F.; Cardoso, A.L.B.D.; Guimarães, C.A.S.; Almeida, L.P.; Neves, R.F.; Sá-Caputo, D.C.; Moreira-Marconi, E.; Dionello, C.F.; Morel, D.S.; Paineiras-Domingos, L.L.; et al. Whole body vibration exercise combined with an extract of Coriandrum sativum modify some biochemical/physiological parameters in rats. Biosci. Rep. 2017, 37, BSR20170070. [CrossRef]

26. Emordi, J.E.; Agbaje, E.O.; Oreagba, I.A.; Iribhogbe, O.I. Antidiabetic and hypolipidemic activities of hydroethanolic root extract of Uvaria chamae in streptozotocin induced diabetic albino rats. BMC Complement. Altern. Med. 2016, 16, 468. [CrossRef] 
27. Frederico, E.H.F.F.; Carmo, F.S.; Diniz, C.L.; Dantas, M.P.; Amorim, L.F.; Santos-Filho, S.D.; Bernardo-Filho, M. Influence of an aqueous extract of Coriandrum sativum leaves on the labeling of blood constituents with technetium-99m and determination of some of its physical parameters. J. Med. Plant Res. 2012, 6, 5651-5657.

28. Celik, F.; Gomez, C.; Bozkurt, M.; Kaplan, I.; Kamasak, K.; Akil, E.; Uzar, E. Neuroprotective effects of carvacrol and pomegranate against methotrexate-induced toxicity in rats. Eur. Rev. Med. Pharmacol. Sci. 2013, 17, 2988-2993.

29. Wellington, D.; Mikaelian, I.; Singer, L. Comparison of ketamine-xylazine and ketamine-dexmedetomidine anesthesia and intraperitoneal tolerance in rats. J. Am. Assoc. Lab. Anim. Sci. 2013, 52, 481-487.

30. Tomczak, M.; Tomczak, E. The need to report effect size estimates revisited. An overview of some recommended measures of effect size. Trends Sport Sci. 2014, 21, 19-25.

31. Ogawa, T.; Zhang, X.; Naert, I.; Vermaelen, P.; Deroose, C.M.; Sasaki, K.; Duyck, J. The effect of whole-body vibration on peri-implant bone healing in rats. Clin. Oral Implants Res. 2011, 22, 302-307. [CrossRef] [PubMed]

32. Amin, A.E.L.; Kareem, M.A.; Yahia, A.B. Influence of low grade exercise on skeletal scintigraphy using Tc-99m methylene diphosphonate. Nucl. Med. Rev. 2015, 18, 61-64. [CrossRef] [PubMed]

33. Frederico, E.H.F.F.; Sá-Caputo, D.C.; Moreira-Marconi, E.; Guimarães, C.A.S.; Cardoso, A.L.B.D.; Dionello, C.F.; Morel, D.S.; Sousa-Gonçalves, C.R.; Paineiras-Domingos, L.L.; Costa-Cavalcanti, R.G.; et al. Effect of mechanical vibration generated in oscillating/vibratory platform on the concentration of plasma biomarkers and on the weight in rats. Afr. J. Tradit. Complement. Altern. Med. 2017, 14, 52-58. [CrossRef] [PubMed]

34. Monteiro, M.O.B.; Sá-Caputo, D.C.; Moreira-Marconi, E.; Frederico, E.H.F.F.; Sousa-Gonçalves, C.R.; Bernardo, L.C.; Guimarães, C.A.S.; Bernardo-Filho, M. Effect of a short period whole body vibration with $10 \mathrm{~Hz}$ on blood biomarkers in Wistar rats. Afr. J. Tradit. Complement. Altern. Med. 2017, 14, 11-18. [CrossRef]

35. Erceg, D.N.; Anderson, L.J.; Nickles, C.M.; Lane, C.J.; Weigensberg, M.J.; Schroeder, E.T. Changes in bone biomarkers, $\mathrm{BMC}$, and insulin resistance following a 10-week whole body vibration exercise program in overweight Latino boys. Int. J. Med. Sci. 2015, 12, 494-501. [CrossRef]

36. Chen, W.C.; Chen, Y.M.; Huang, C.C.; Tzeng, Y.D. Dehydroepiandrosterone supplementation combined with whole-body vibration training affects testosterone level and body composition in mice. Int. J. Med. Sci. 2016, 13, 730-740. [CrossRef]

37. Sun, C.; Zeng, R.; Cao, G.; Song, Z.; Zhang, Y.; Liu, C. Vibration training triggers brown adipocyte relative protein expression in rat white adipose tissue. Biomed Res. Int. 2015, 919401. [CrossRef]

38. Lin, C.I.; Huang, W.C.; Chen, W.C.; Kan, N.W.; Wei, L.; Chiu, Y.S.; Huang, C.C. Effect of whole-body vibration training on body composition, exercise performance and biochemical responses in middle-aged mice. Metabolism 2015, 64, 1146-1156. [CrossRef]

39. Cardoso, A.L.B.D.; Frederico, É.H.F.F.; Guimarães, C.A.S.; Almeida, L.P.; de Figueiredo Neves, R.; de Sá-Caputo, D.; Moreira-Marconi, E.; Dionello, C.F.; Morel, D.S.; Paineiras-Domingos, L.L.; et al. Chenopodium ambrosioides associated with whole body vibration exercises alters the feed intake in Wistar rats. Biosci. Rep. 2017, 37, BSR20170846. [CrossRef]

40. Usmanghani, K.; Saeed, A.; Alam, M.T. Indusyunic Medicine: Traditional Medicine of Herbal, Animal and Mineral Origin in Pakistan; BCC and T Press, University of Karachi: Karachi, Pakistan, 2003.

41. Nieto, M.D.L.L.; Wu, J.M.; Matthews, C.; Whitehead, W.E.; Markland, A.D. Factors associated with fecal incontinence in a nationally representative sample of diabetic women. Int. Urogynecol. J. 2015, 26, 1483-1488. [CrossRef]

(C) 2019 by the authors. Licensee MDPI, Basel, Switzerland. This article is an open access article distributed under the terms and conditions of the Creative Commons Attribution (CC BY) license (http://creativecommons.org/licenses/by/4.0/). 